\title{
EFFECTIVE INDEPENDENT QUALITY ASSESSMENT USING IV\&V
}

\author{
Pathanjali Sastri Akella ${ }^{1}$ and K. Nageswara Rao ${ }^{2}$ \\ ${ }^{1}$ Lecturer, Department of Computer Applications, V.R.Siddhartha Engineering \\ College, Kanuru, Vijayawada-7. \\ akellapatanjali@yahoo.com \\ ${ }^{2}$ Professor \& Head, Department of Computer Science and Engineering, \\ P.V.P.Siddhartha Institute of Technology, Kanuru, Vijayawada-7. \\ drknrao@ieee.org
}

\begin{abstract}
Software is critical to the effectiveness, competitiveness, and survival of any organization. Unexpected behavior or critical problems that bring operations to an idle are just not an option. Effective oversight is critical to good project management and as it is important for the project manager to ensure that the project is on track and to be completed within the estimated schedule and cost by maintaining the quality of the deliverables. This paper describes the role of Independent Verification and Validation $(I V \& V)$ integrated into the software development life cycle in bringing down company's cost to develop software products, improve the quality of developed systems and save money throughout the system life cycle by detecting and identifying risk elements throughout the entire software development process thus allowing project and quality assurance managers to respond quickly in order to mitigate risks earlier in the product development life cycle, with more effectiveness, and with less impact on cost and schedule.
\end{abstract}

\section{KEYWORDS}

$S Q A, I V \& V$, verification, validation, Independence, Project Management, Risk Management Approach

\section{INTRODUCTION}

Many software companies have Software Quality Assurance (SQA) functions within their organizations. Yet, high profile software failures continued to occur as SQA is not living up to expectations. It is very important that the project and the SQA collaborate and plan the activities that are appropriate at each phase based on risks and resources. If SQA teams lack the experienced associates having domain \& technical expertise, it becomes difficult to determine root cause and solutions to scheduling, cost, and quality issues in projects. But in most of the organisations SQA does not focus on opportunities for early error detection, problem prevention, and risk identification, but focuses more on evaluating processes and products with emphasis on monitoring processes to ensure the quality of the delivered product. This means SQA, ensures compliance to standards and procedures but on the other hand, there is a gap in employing rigorous methodologies for evaluating the correctness and quality of the software product throughout the software life cycle. IV\&V which is independent from the Project is expected to do reviews, inspections, causal analysis, implement best practices and testing to provide a high-degree of assurance on the level of operational risk and earlier detection \& prevention of errors in the life cycle by employing rigorous methodologies for evaluating the correctness and quality of the software product throughout the software life cycle. A recent study conducted by the Standish Group on the success of IT projects over a 12-year period revealed that though IT project performance has

DOI : 10.5121/ijcsit.2011.3313 
improved in recent years, the projects continue to have issues and failures. Now-a-days as we develop complex and high-criticality (e.g. safety-critical) systems, a separate entity (within the organization or a separate external consultancy) independent from the developer, will often be needed to perform independent verification and validation (IV\&V) with the purpose of assessing the correctness and quality of a project's product.

This paper discusses the functions of IV\&V which ensures the product meets the requirements and controls the cost of the system life cycle, improve the quality of systems, and strengthen the IT organization. Section 2 describes the challenges faced by QAG; Section 3 describes differences between prevention and correction; section 4 to Section 6 proposes the SQA embedded with IV\&V activities and importance of IV\&V role in projects; and finally Section 7 discusses about the successful implementation of IV\&V program.

\section{Challenges Faced by Quality Assurance grouP}

In current process models such as CMMI, the quality assurance function is supposed to detect process and standards-oriented issues, resolve them within the project, or escalate them to senior management. Quality Assurance (QA) is also responsible for identifying, managing, and implementing software process improvement (SPI), but QA groups become more like quality control, checking things well after the time when detecting a problem would have been useful. The following are various activities performed by QA group in any organization. SQA in many organisations is not effective as the team could not execute their processes in concurrent with project activities. Unfortunately, that is difficult to do and detect problems timely enough to be of value as the SQA teams lack the functional, managerial, and financial independence to act effectively as an advocate for the projects [1].

The following are the reasons for the challenges faced by Quality Assurance group in software projects.

a. Complexity of software developed now-a-days increased significantly.

b. Competitive business pressures also increased significantly.

c. Software was being used in many new areas - especially areas that were lifethreatening.

d. Many people working in SQA received little formal training in SQA and are expected to learn primarily from on-the-job training.

\section{Prevention versus Detection}

Figure 1 shows that the cost to find and fix defects increases significantly as software development and deployment proceeds. Thus it is vital to put more emphasis on early error detection and correction. The cost to correct software errors increases in geometric progression during software development life cycle. Early detection and correction reduce costs and save time. Moreover, by its very nature, mission-critical software is a complex entity. Failure to perform IV\&V for software projects could result in software system weaknesses, performance of unintentional functions, and failure of the system and the mission [2]. A philosophy of detection is based on the hypothesis that defects will be identified and then corrected. A strategy of prevention is formed from the fact that defects can be avoided altogether through the application of various techniques [3]. 


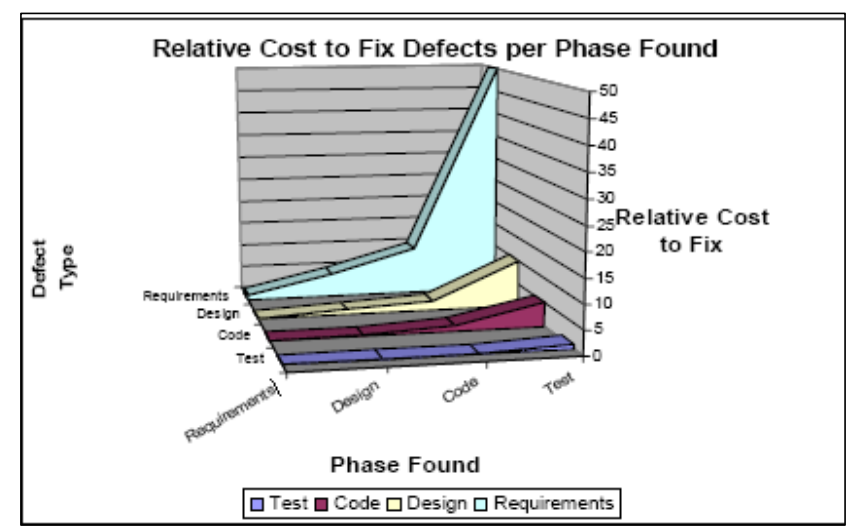

Figure 1: Direct ROI of Software IV\&V Methodology and Initial Case Studies.James B.Dabney and Gary Barber, Assurance Technology Symposium, 5th June 2003.

So, there is a need for an independent quality assurance group embedded with an independent verification \& validation team to establish more formal QA process than the one currently employed and mitigate the risk of project failures, schedule delays, or cost over-runs. This ensures that the system is being developed as per requirements of the customer and is reliable as it is built with sound engineering practices. NASA has used IV\&V for software projects that require high reliability, such as in the case of the Shuttle Program and the Space Station Program which are expensive and have a high degree of risk where there are high potential social or financial loss resulting from an operational failure, the cost of IV\&V is considered a worthwhile investment [4].

\section{ESTABLISHING INDEPENDENCE}

The IEEE Standard for Software Verification and Validation identifies three parameters that define the independence of IV\&V: Technical (achieved by IV\&V experts who use their expertise to assess development processes and products independent of those performing the development team), Managerial (IV\&V effort to be vested separate from the development and project management activity), Financial (funding needs to allocated separately by the organization in order to insulate the IV\&V team from any potential financial pressures). The following table (Table 1) discuses various QA/IVV independence types [5]:

Table 1: various QA/IVV independence types (Source: IEEE 1012)

\begin{tabular}{|c|c|}
\hline Independence Type & Description \\
\hline \multirow{4}{*}{ Classical } & $\begin{array}{l}\text { In this case, Responsibilities for SQA/IV\&V efforts are } \\
\text { provided by an organization that has: }\end{array}$ \\
\hline & $\begin{array}{l}\text { Managerial independence from the development and } \\
\text { program management organizations }\end{array}$ \\
\hline & $\begin{array}{l}\text { Financial independence, with control of the SQA/IV\&V } \\
\text { budget independent of the development organization }\end{array}$ \\
\hline & $\begin{array}{l}\text { Technical independence, with technical personnel not } \\
\text { involved in the development of the software }\end{array}$ \\
\hline SQA/IV \&V Modified & $\begin{array}{l}\text { In this case, managerial independence is compromised } \\
\text { since the SQA/IV\&V service provider reports directly to } \\
\text { the prime integrator. This approach still maintains technical } \\
\text { and financial independence, since an outside organization is }\end{array}$ \\
\hline
\end{tabular}




\begin{tabular}{|c|l|}
\hline & $\begin{array}{l}\text { providing the SQA/IV\&V services and there is a separate } \\
\text { budget set aside for these services. }\end{array}$ \\
\hline SQA/IV\&V Internal & $\begin{array}{l}\text { In this case, the developer is responsible for SQA/IV\&V } \\
\text { activities using personnel from its own organization, though } \\
\text { not necessarily the same personnel involved in the } \\
\text { development effort. In this case, all technical, managerial, } \\
\text { and financial independence is compromised to some } \\
\text { extent. }\end{array}$ \\
\hline $\begin{array}{c}\text { SQA/IV \&V } \\
\text { Embedded V\&V } \mathbf{V}\end{array}$ & $\begin{array}{l}\text { This is similar to Internal SQA/IV\&V except that } \\
\text { personnel on the development team also perform the V\&V } \\
\text { activities, thus maintaining no real measure of } \\
\text { independence. }\end{array}$ \\
\hline
\end{tabular}

Independent Verification and Validation is not merely SQA and both perform distinct tasks. SQA functions as a part of the Project Team or as a separate team to provide daily insight/oversight by evaluating processes and products with emphasis on monitoring processes to ensure the quality of the delivered product and compliance to standards and procedures [6]. IV\& V typically focus on either the software development process or the products produced by that process and involves an independent analysis of the work products resulting during development and after delivery. As explained in Table 1, the independence may not be of a SQA/IV\&V Modified type, but can be any of SQA/IV\&V Internal or SQA/IV\&V Embedded $V \& V$ and SQA/IV\&V Embedded V\&V is a preferred one. One consistent aspect of IV\&V is that the team that is involved is independent of the project team and project management and is tasked with providing an unbiased assessment of the quality of the project deliverables. Comprehensive, fully independent, IV\&V is justified when the risk from software failure is high [7]. IV\&V team traditionally ensures that work products conform to designated or agreed-upon standards, requirements, quality methods, and project plans throughout the course of the SDLC and maintenance. The activities of IV\&V include assessment, analysis, evaluation, review, inspection, and testing of software products and processes and methods typically present findings (i.e. nonconformance) detected by evaluation methods (for example, audits, reviews, tests, and so on) followed by rework and tracking of the rework to closure.

\subsection{Avoiding negative culture - Adopting SQA/IV\&V Embedded IV\&V}

In the so called IVV model, the validation team is physically separated and given full independence to report the test results to the developers. Separation of software testing from software development creates a culture of conflict based on negativity. The use of independent testing shifts the ownership of quality away from the development team as the development believes that testing is not their responsibility. Also having separate teams with conflicting agendas to attack each other is not the path to quality. Instead of maintaining a separate IV/V group (SQA/IV\&V Modified type as referred in Table 1), it is cost-effective to establish specialized software quality expertise within the same software company to review and validate every deliverable produced by a project team work closely with the development team from the beginning of the project and performs its validation and verification efforts on a day-to-day basis throughout the project lifecycle providing feedback and audit results on an on-going basis. The advantage is that this approach allows for earlier and therefore likely more cost effective resolution of identified problems as the project and the QA/IVV team will work together to negotiate what activities are appropriate at each phase based on risks and resources.

For example, recent developments in technology, such as SOA and component based software development are expected to have a significant impact on testing and mandate a fundamental 
change in the mindset of a testing professional. SOA offers a way to more flexibly meet requirements by aligning technology with business needs but this model makes software more complex and interconnected. So, independent testing cannot be performed until the software is completed, assembled, and deployed into a testing environment. There is no time left for rework if defects are found at this point. Also use of independent testing transfers the ownership of quality away from the development team as the development team thinks that testing, and quality control is not their responsibility. To increase business agility, while reducing the risks of change and complexity in software, the IV/V team needs to work alongside development and business teams to ensure quality throughout the design, development, and change lifecycles of SOA software. With no proven tools or frameworks currently available, Quality Assurance teams continue experimenting with ways to address the SOA testing challenge. It is worth noting that it does not make a make good business sense as separation of the quality function from the developer is counter-productive, infects morale, and defeats software quality objectives.

\subsection{Budget for QA/IV\&V}

IV\&V activities comprise 5-10 percent of a project's overall budget and this investment should be understood in the context of the overall "cost of quality" within the project [4]. The objective of any project should be to minimize overall costs, which means fixing bugs as early as possible in the life cycle of the project. Hence, the wisdom of using IV\&V, which is considerably less costly than correcting bugs in the later stages and must be implemented to help prevent them occurring in the first place.

\section{Projects without IV\&V}

Cost of Quality $(\mathrm{CQ})=$ cost of investments intended to improve the quality of products and services $(\mathrm{CP})+$ including prevention costs and review costs $(\mathrm{CPR})+$ the cost of fixing bugs both prior to or after the completion of the project (CFB) [8].

\section{So, $\mathrm{CQ}=\mathrm{CP}+\mathrm{CPR}+\mathrm{CFB}$}

Projects with IV\&V:

$\mathrm{CQ}=\mathrm{CP}+\mathrm{CPR}+\mathrm{CFB}-\Delta \mathrm{X}, \Delta \mathrm{X}=$ the cost incurred on correcting bugs of particularly late-stage deficiencies

Working within the framework of the organisation's formal processes and procedures, IV\&V provides an audit function that ensures that information systems developed meet the customer's requirements can save the organization as much as $15 \%-20 \%(\Delta \mathrm{X})$ of the life cycle cost of a system because errors caught early in the development process cost less to fix than errors caught and corrected once the system is in production. Figure 2 below depicts the effect on COQ with and without the implementation of IV\&V. 

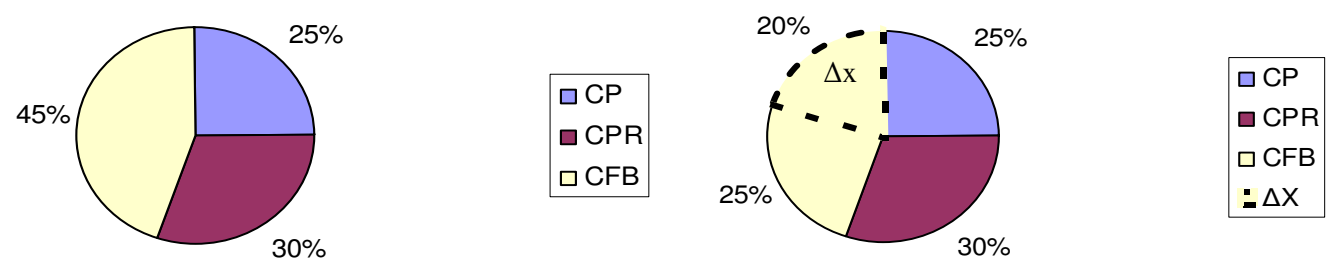

Figure 2: Effect on Cost of Quality with and without the implementation of IV\&V

IV\&V can be employed on only those processes and products determined to have the highest risk, and require an in-depth evaluation of them. So, it is useful if IV\&V is embedded within SQA [6] where appropriate and are conducted independently of the Development team. Table 2 below shows the significant differences between SQA and IV\&V.

Table 2: QA and IV\&V focus areas

\begin{tabular}{|l|l|}
\hline SQA & IV\&V \\
\hline $\begin{array}{l}\text { Emphasizes compliance to } \\
\text { standards and procedures }\end{array}$ & $\begin{array}{l}\text { Emphasizes completeness and } \\
\text { correctness of the product }\end{array}$ \\
\hline $\begin{array}{l}\text { Reviews, monitors and audits all } \\
\text { Project processes and products for } \\
\text { completeness and accuracy }\end{array}$ & $\begin{array}{l}\text { Reviews, analyzes, and provides in- } \\
\text { depth evaluations of life cycle } \\
\text { products which have the highest risk }\end{array}$ \\
\hline $\begin{array}{l}\text { Matrixed to the Project as part of } \\
\text { the Project Team and provides } \\
\text { daily insight/oversight }\end{array}$ & $\begin{array}{l}\text { Independent from the Project and } \\
\text { provides analyses and evaluations per } \\
\text { IV\&V priorities }\end{array}$ \\
\hline
\end{tabular}

\subsection{Project management assessment by IV\&V as an important task}

In recent years, many projects have attempted to promote project success by enhancing project processes and more closely monitoring outcomes. These efforts have included improved project management practices, use of analytic techniques such as Earned Value Management (EVM) that combines schedule performance and cost performance to answer the question, "What did we get for the money we spent?" In many cases, the efforts have not sufficiently addressed project risks because the steps taken were intended to serve as warning signals, rather than ways to prevent or solve problems. So, a Project Management Office (PMO) often focuses on evaluating cost and schedule factors associated with EVM, but often lack the objectivity needed to provide the necessary evaluation of project quality. Instead of approaching a separate group to record non-conformances, it is mandatory to consider establishing a specialized software quality expertise within the development team who interacts with IV\&V and SQA teams to prevent the rework. Thus a role has to be created for a dedicated quality specialist within the software development team as in SQA/IV\&V Embedded V\&V type (explained in section 4), who guards against groupthink as a member of the software development team, so that the development group and project management will work collaboratively with the SQA \& IV\&V team, to ensure their project deliverables are compliant with standards and best practices. This enables the Project Manager to utilize the services of QA Team and IV\&V Team as shown in the table 3 and work in collaborative mode. 
International Journal of Computer Science \& Information Technology (IJCSIT), Vol 3, No 3, June 2011

Table 3: Table depicting the utilization of services of QA and IV\&V by Project Manager

\begin{tabular}{|l|l|l|}
\hline Factors & QA Team & IV\&V Team \\
\hline $\begin{array}{l}\text { Business } \\
\text { Needs }\end{array}$ & $\begin{array}{l}\text { QA perform evaluations with the } \\
\text { Project team }\end{array}$ & $\begin{array}{l}\text { QA suplemented with Subject Matter } \\
\text { Experts }\end{array}$ \\
\hline $\begin{array}{l}\text { Inegree of } \\
\text { ce }\end{array}$ & $\begin{array}{l}\text { Small projects with low risks } \\
\text { independence is not essential, a } \\
\text { QA team could perform the } \\
\text { entire product evaluations, with } \\
\text { a minimal IV\&V effort focused } \\
\text { on processes. }\end{array}$ & $\begin{array}{l}\text { High degree of independence for the } \\
\text { verification and validation activities, } \\
\text { calling for an emphasis on IV\&V for } \\
\text { the projects involving complexity, } \\
\text { competitive business pressures, and } \\
\text { machine critical applications. }\end{array}$ \\
\hline $\begin{array}{l}\text { Available } \\
\text { skills and } \\
\text { domain } \\
\text { knowledge }\end{array}$ & $\begin{array}{l}\text { A project's staff may have } \\
\text { strong business domain } \\
\text { knowledge, but limited software } \\
\text { development experience. This } \\
\text { would call for a QA to perform } \\
\text { quality reviews on business } \\
\text { requirements and functional } \\
\text { testing. }\end{array}$ & $\begin{array}{l}\text { IV\&V concentrating on technical } \\
\text { requirements, code reviews, and } \\
\text { system performance testing. }\end{array}$ \\
\hline $\begin{array}{l}\text { Dependenc } \\
\text { e } \\
\text { Flexibility }\end{array}$ & $\begin{array}{l}\text { For complex projects, } \\
\text { anticipating the problem areas } \\
\text { will be difficult, so the project } \\
\text { manager may rely more heavily } \\
\text { on QA resources }\end{array}$ & $\begin{array}{l}\text { Project Manager may keep greater } \\
\text { control/insight of project's oversight } \\
\text { most tasks and supplementing with } \\
\text { IV\&V only for critical areas }\end{array}$ \\
\hline
\end{tabular}

\section{IV \& V'S RISK-BASED APPROACH FOR PREVENTING THE AREAS OF HIGHEST RISK}

A recent study of IT projects by the Institute of Electrical and Electronics Engineers (IEEE) revealed that the cost of correcting a defect in the testing phase is over fifty times the cost of correcting the same defect in the requirements phase. Through proactive review of project management, and product development, the processes needed to deliver the project successfully are in place are determined and then execution of the project is monitored. IV\&V's risk-based approach helps to ensure that stakeholder requirements are being addressed early on and as a forward-looking approach [6]. This helps to identify areas within the project that might cause problems and identify risks before they become full-blown problems that are more costly to fix. These risks are brought to the attention of management, and in addition, when problems are identified, IV\&V can help identify the root causes so mistakes are not repeated, thus focus on preventing the areas of highest risk. This approach is applied over the full life cycle of a project, so that comprehensive risk assessment is designed to help the project meet business requirements, keep milestones and deliverable dates, stay within budget, deliver intended benefits and more important identify priorities for management of risks in line with the magnitude and probability of a risk's impact on outcomes.

If IV\&V team performs validation and verification efforts only at specific milestones of the project or at pre-agreed intervals or only at the end of the project to provide final review, audit, and approval to go-live, then the project may have to miss a deadline or a critical milestone because the IV\&V will start its investigation at the end of the phase or end of the project. The advantage of this approach is that this is likely to be a least expensive IV\&V operation. However, the errors reported here do not include the errors found and eliminated by 
the developer, i.e., the errors reported here are only those found by IV\&V. If the investigators try to determine the root cause(s) of the delay, which may be an inadequate plan, process, or product at the end of the phase throughout the project, this causes small delays at each phase and thus cause a large overall delay. If IV\&V was not employed and therefore not finding errors, the number of errors found by the developer in code and test phase or later would be compounded by an amount proportional to the number of errors found by IV\&V in requirements gathering and design phases. If IV\&V takes place in parallel with development, these errors are found earlier when they are cheaper to fix. Therefore if IV\&V is not active until later in the life cycle, the errors that could have been discovered earlier are still there to be discovered and corrected later at a higher cost [9]. There should be a structured approach for risk assessment and is required for projects should perform a risk assessment during the early planning stage, come out with a risk-adjusted life-cycle cost estimate and a plan to eliminate, mitigate or manage risk, and also all major projects are required to have a risk management plan prior to moving from planning into the development phase. So, IV\&V continuously evaluates the effectiveness of management processes in the areas of project governance, risk/issue management, deliverable quality, and requirements management, in addition to tracking the deliverables timeline. By reviewing these focus areas, the IV\&V team will be able to facilitate an early confirmation that project requirements would be fully met and that the resulting system would be of the expected quality. These assessments will serve as the basis for much of the management reporting and decision making.

\section{IV\& V CENTER OF EXCELLENCE}

The economic benefit could be realized from IV\&V when errors are found earlier in the life cycle than they might otherwise have been found during testing phase or before delivery. Boehm estimated that the cost to fix an error for large projects increases by $20 \%$ if detected at phase $2,25 \%$ at phase $3,75 \%$ at phase 4 , and $200 \%$ at phase 5 relative to the cost to fix the error at phase 1 as shown figure 3 . There is a need for IT organisations today to evaluate ways and means of optimizing verification \& validation costs. Independent Verification Validation Group is a V\&V Centre of Excellence formed by a group of experienced testers, DE or SMEs, Technical architects, Auditors, \& software experts. Thus an IV\&V group being an extremely knowledgeable, responsive, and professional support team gives companies the ability to reduce testing costs while increasing its efficiency. Highest software quality is achieved by taking advantage of a global pool of talent, greater expertise, continuous investment in new methodologies, process improvements and by providing active quality assurance throughout the development life cycle of the project and independent verification \& validation services. In order to achieve, the following services are required in all the phases of the project and ultimately this means that they can improve the quality of their software, reduce the time it takes to bring them to market and improve their brand image.

\section{Cost of correcting defects}

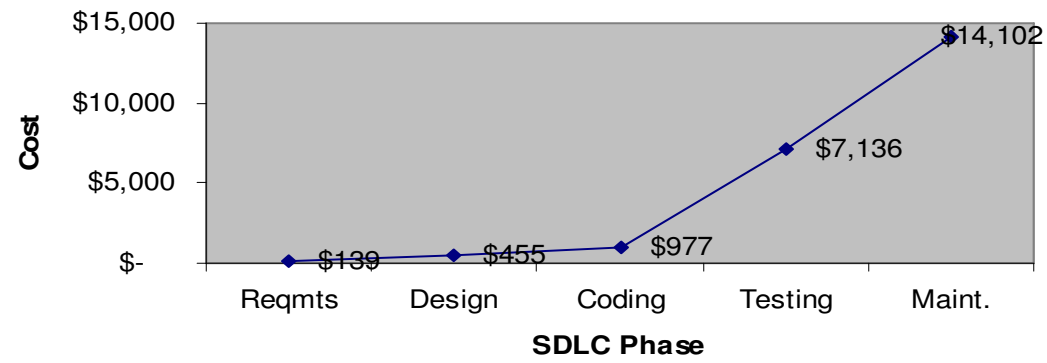

Figure 3: Source: B. Boehm and v. Basili, "software defect reduction Top 10 List," IEEE Computer 


\section{Building a SucCessful IV\&V Program}

The following criteria can trigger mandated IV\&V assessment:

a. For those projects that failed to meet a critical milestone

b. For those projects that failed to deliver the software as per schedule and within the cost budget. and

c. For those that need for a total system redesign and those projects that are machine critical.

We need to establish IV\&V Center of Excellence to monitor the quality of our products and services, and ensure that each deliverable meets our high standards. The IV\&V Methodology should be employed with lessons learnt from large and complex IT projects and leverages industry standards and best practices, including Software Engineering Institute's (SEI) Capability Maturity Model Integration (CMMI), Institute of Electrical Electronics Engineering (IEEE) Standards 1012-2004 (Standard for Software Verification and Validation), Project Management Institute's (PMI) Project Management Body of Knowledge (PMBOK) and ISO 9001 Standards [1]. In addition to these, we need to have a Quality Assurance (QA) and IV\&V Process Asset Library (PAL) to store IV\&V plans, processes, templates, checklists, examples, and industry best practice standards and white papers to enable us to provide customers with a more efficient process by minimizing project start-up time and establishing a sound foundation for our QA and IV\&V services.

The following example illustrates how an IV\&V team works with all the stakeholders to help them realize their goals in a large-scale development project with formal reviews at the end of each phase. The model can be adapted for smaller jobs where there is less risk, or for iterative development methodologies such as Rapid Application Development (RAD). The projectmodel of IV\&V is well known and the most often implemented. In this model, each IT project uses its own IV\&V reviewer who in turn brings to bear its processes, procedures and methodologies. As a result, multiple projects within the same organization may not receive IV \&V services in a consistent manner. The organization level IV\&V provides the same process, procedures, and methodologies to each project within the organization and all the projects receive the same IV\&V process, procedures, and methodologies as shown in the figure 4 below.



Figure 4: QA/IV\&V Model at Organizational level 
IVV is a risk mitigation technique and has to be empowered with the following:

(a) Assess the approach the project has taken to complete its task

(b) Monitor the work of the project team and Identifying their accomplishments

(c) Advising the senior management how the project team is achieving against the terms of their contract and

(d) Review the proposals along with SQA and steering committee and recommends projectselection decision making to the Senior Management

Thus the establishment of IV\&V center of excellence provides a way where the ideas are leveraged by other active projects and thus exploiting these resources would be of the organisation's best advantage.

\section{CONCLUSIONS}

In some cases the IV\&V simply tests a particular system as a second opinion on readiness, after the project team has completed development and testing in order to verify and validate that the system has been thoroughly tested and is ready for the delivery. In other cases, the IV \&V organization reviews and validates every deliverable produced by a project team (e.g. all requirements documents, design documents, code, system configurations, validates test cases, re-runs test cases, and audits and reviews all testing results). Though verification and validation activities don't have to be performed independently, however, independence (independent of the project team within the organization and need not be a third party) assures objective feedback about project status. IV \&V method which is an extension of the project management and systems engineering team, and undertakes to proactively identify objective data about product quality, performance, and schedule compliance for the development organization which can typically be used in real-time critical projects in an organization that cause a high cost of failure, thus early feedback results allow the development organization to modify the software products and processes quickly and reduce overall project cost and schedule.

Although there are industry-specific or domain-specific standards on how mission-critical software should be developed, future research should address a set methodology for doing product/project inspections, as until now, there is still no consensus or standard as to how the conformance to standards should itself be verified.

\section{REFERENCES}

[1] David F. Wagoner, (2008) "A Hybrid Approach for Overcoming Common IV\&V Challenges", Software Quality Professional (SQP), VOL. 11, pp. 26-28.

[2] Preferred Reliability Practices (Practice No. Pd-Ed-1228) Independent Verification And Validation Of Embedded Software, NASA, pp:1

[3] John R. Snyder, (Nov 2003)“Software Testing-Independent or interdependent?”, URL: http://www.snyders.us/interdependent-testing.htm

[4] Ralph D. Neal, Dan McCaugherty, Tulasi Joshi, and John Callahan, (1997 ) "A CASE STUDY OF IV\&V COST EFFECTIVENESS", NASA/WVU Software IV \& V Facility, Software Research Laboratory Technical Report Series, pp 1-9,

[5] Dolores R. Wallace, Laura M. Ippolito, Barbara Cuthill, Reference Information for the Software Verification and Validation Process, URL: http://hissa.nist.gov/HHRFdata/Artifacts/ITLdoc/234/val-proc.html

[6] Dolores R.Wallace, Roger U. Fujii, (1989) "Software Verification and Validation-An Overview", IEEE, pp 10-17. 
International Journal of Computer Science \& Information Technology (IJCSIT), Vol 3, No 3, June 2011

[7] Jon Hagar, Lisa Boden "How to Build a 20-Year Successful Independent Verification and Validation (IV\&V) Program for the Next Millennium”, Lockheed Martin Astronautics Company, pp:5

[8] Richard Stonehouse-Software Quality Consultant, URL: http://www.rstonehouse.co.uk

[9] Brian Lawrence, Karl Wiegers, and Christof Ebert, (2001) "The Top Risks of Requirements Engineering", IEEE, pp 62-63,

\section{Authors}

Mr. A.Pathanjali Sastri is currently pursuing Ph.D Computer Science from Raylaseema University, Kurnool. He is woking as a Lecturer in Velagapudi Siddhartha Engineering college since 2008 and has 10 years of Industrial experience prior to this. He has published papers in reputed international journals and conferences. His area of interest includes Software Engineering, Quality Assurance, Artificial Intelligence and RDBMS.

Dr. K. Nageswara Rao is Currently working as Professor \& Head, Department of Computer Science Engineering, in Prasad V. Potluri Siddhartha Institute of Technology, Kanuru, Vijayawada-7. He has an excellent academic and research experience. He has contributed various research papers in the journals, conferences of international/national repute. His area of interest includes Artificial Intelligence, Software Engineering, Robotics, \& Datamining.
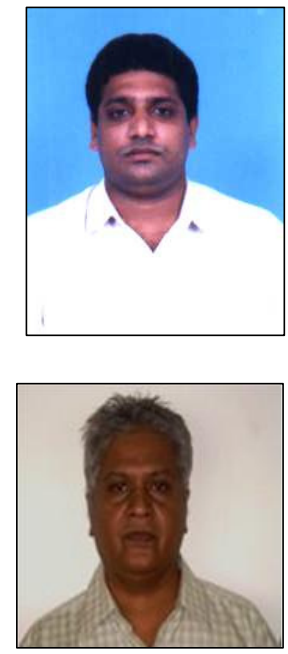